\title{
2 Making Sense of Sense-Making: Reflections on Enactive 3 and Extended Mind Theories
}

\author{
4 Evan Thompson - Mog Stapleton
}

\author{
(C) Springer Science+Business Media B.V. 2008
}

\begin{abstract}
This paper explores some of the differences between the enactive approach in cognitive science and the extended mind thesis. We review the key enactive concepts of autonomy and sense-making. We then focus on the following issues: (1) the debate between internalism and externalism about cognitive processes; (2) the relation between cognition and emotion; (3) the status of the body; and (4) the difference between 'incorporation' and mere
\end{abstract} 'extension' in the body-mind-environment relation.

Keywords Enaction - Extended mind - Autonomy · Sense-making $\cdot$ Emotion $\cdot$ Embodiment $\cdot$ Incorporation

According to the enactive approach in cognitive science, cognition is grounded on the sense-making activity of autonomous agents-beings that actively generate and sustain themselves, and thereby enact or bring forth their own domains of meaning and value (Thompson 2007; Varela et al. 1991). According to the extended mind thesis, the environment constitutes part of the mind when it is coupled to the brain in the right way (Clark and Chalmers 1998). Although both viewpoints stress the crucial contributions that the body and the environment make to cognition, recent discussions have emphasized how these

E. Thompson $(\bowtie)$

Department of Philosophy, University of Toronto,

170 St. George Street, Toronto, ON, Canada M5R 2M8

e-mail: evan.thompson@utoronto.ca

M. Stapleton

Department of Philosophy, University of Edinburgh,

Edinburgh EH8 9AD, Scotland, UK

e-mail: M.L.Stapleton@sms.ed.ac.uk views also differ in significant ways (Clark 2008; Di Paolo this issue; Wheeler in press).

Our aim here is to examine some of these differences, particularly as seen from the enactive perspective. We do not intend to offer detailed arguments supporting the enactive perspective. Rather, we wish to call attention to some of the distinctive features of the enactive approach compared with the extended mind thesis in order to provoke future discussion and debate.

After first reviewing certain core ideas of the enactive approach, we focus on the following issues: (1) the debate between internalism and externalism about cognitive processes; (2) the relation between cognition and emotion; (3) the status of the body; and (4) the difference between 'incorporation' and mere 'extension' in the body-mindenvironment relation.

\section{The Enactive Approach}

The enactive approach is based on a number of mutually supporting core concepts, such as autonomy, sense-making, emergence, embodiment, and experience (De Jaegher and Di Paolo 2007; Thompson 2004, 2007; Varela et al. 1991). Here we emphasize the two crucial concepts of autonomy and sense-making.

\subsection{Autonomy}

The enactive approach does not start from the question of whether cognitive processes extend beyond one or another boundary, such as the skin, skull, or central nervous system, that is supposed to mark some inside/outside distinction. Rather, the enactive approach starts from the question of how a system must be organized in order to

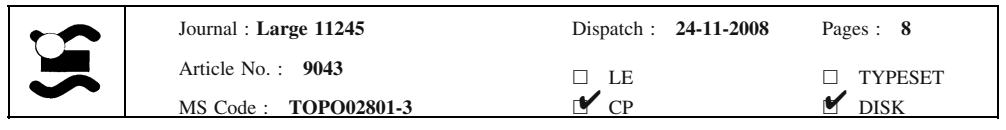


61 be an autonomous system - one that generates and sustains

62 its own activity and thereby enacts or brings forth its own 63 cognitive domain.

64

65

66

67

68

69

The paradigm cognitive beings are living organisms. According to the enactive approach, what makes living organisms cognitive beings is that they embody or realize a certain kind of autonomy-they are internally self-constructive in such a way as to regulate actively their interactions with their environments (Di Paolo and lizuka 2008; Thompson 2007; Varela 1979, 1997; Varela and Bourgine 1991). Thus autonomy is the crucial organizational property we need to understand if we aim to understand how a system can be cognitively related to the world.

An autonomous system is a system composed of processes that generate and sustain that system as a unity and thereby also define an environment for the system. Autonomy can be characterized abstractly in formal terms or concretely in terms of its energetic and thermodynamic requirements (Thompson 2007, pp. 44-46). Considered abstractly, for a system to be autonomous, its constituent processes must meet the following conditions:

(1) recursively depend on each other for their generation and their realization as a network;

(2) constitute the system as a unity in whatever domain they exist; and

(3) determine a domain of possible interactions with the world.

This definition captures what Varela $(1979,1997)$ meant when he proposed that the crucial property of an autonomous system is its operational closure. In an autonomous system, every constituent process is conditioned by some other process in the system; hence, if we analyze the enabling conditions for any constituent process of the system, we will always be led to other processes in the system.

Notice that operational closure does not imply that conditions not belonging to the system cannot also be necessary. On the contrary, for any autonomous organization to be physically realized, the operationally closed network of processes must be thermodynamically open. This point takes us to the second way of characterizing autonomy.

Here the main aim is to specify the energetic and thermodynamic requirements for the instantiation of "basic autonomy" in the physical world (Ruiz-Mirazo and Moreno 2004). From this perspective, basic autonomy is "the capacity of a system to manage the flow of matter and energy through it so that it can, at the same time, regulate, modify, and control: (i) internal self-constructive processes and (ii) processes of exchange with the environment" (Ruiz-Mirazo and Moreno 2004, p. 240).
Putting together the abstract and physical ways of characterizing autonomy, we can state in general terms that an autonomous system is a thermodynamically open system with operational closure that actively generates and sustains its identity under precarious conditions. ${ }^{1}$

The paradigm case of an autonomous system is the living cell. The constituent processes in this case are chemical; their recursive interdependence takes the form of a self-producing, metabolic network that also produces its own semipermeable membrane; and this network constitutes the system as a unity in the biochemical domain and determines a domain of interactions with the world. This kind of self-producing autonomy at the molecular level is known as autopoiesis (Maturana and Varela 1980; Varela et al. 1974).

Other candidate autonomous systems include the nervous system, sensorimotor systems, the multicellular body of metazoan organisms, the immune system, and animal and human social groups. ${ }^{2}$ Although these kinds of autonomous systems depend on the autopoiesis of their cellular constituents, they are not necessarily autopoietic. Autopoiesis requires (among other things) that the operationally closed network produce and realize itself as a spatially bounded system (see Bourgine and Stewart 2004; Thompson 2007). This kind of closure is characteristic of the single-cell, metabolic realizations of autonomy and perhaps of multicellular organisms (see Maturana and Varela 1987, pp. 87-89; Thompson 2007, pp. 105-106), but not of distributed systems such as the nervous system, the immune system, insect colonies, and so on. In any case, nothing in principle rules out other ways besides autopoiesis of realizing the autonomous organization. Thus, for the enactive approach, it is not autopoiesis as such that provides the crucial bridge to cognition (pace Wheeler, in press), but rather autonomy. To appreciate this point, we need to ask what sort of autonomy is required for cognition.

\subsection{Sense-Making}

Consider motile bacteria swimming uphill in a food gradient of sugar (Thompson 2007, pp. 74-75, 157-158; Varela 1991). The cells tumble about until they hit upon an orientation that increases their exposure to sugar, at which point they swim forward, up-gradient, toward the zone of greatest sugar concentration. Sugar is significant to these

\footnotetext{
1 The notion of precarious conditions comes from Ezequiel di Paolo: 1FL01 "By precarious we mean the fact that in the absence of the 1FL02 organization of the system as a network of processes, under otherwise 1FL03 equal physical conditions, isolated component processes would tend 1FL04 to run down or extinguish" (De Jaegher and Di Paolo 2007, p. 487). 1FL05 See also Di Paolo's paper in this special issue.

1 FL06

${ }^{2}$ For discussion of how autonomy pertains to these systems, see 2FL01 Thompson (2007) and the further references contained therein. 2FL02
}

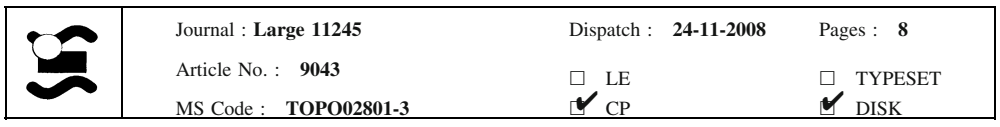


organisms and more of it is better than less because of the way their metabolism chemically realizes their autonomous organization. The significance and valence of sugar are not intrinsic to the sugar molecules; they are relational features, tied to the bacteria as autonomous unities. Sugar has significance as food, but only in the milieu that the organism itself enacts through its autonomous dynamics.

This example is meant to illustrate that even the simplest organisms regulate their interactions with the world in such a way that they transform the world into a place of salience, meaning, and value-into an environment (Umwelt) in the proper biological sense of the term. This transformation of the world into an environment happens through the organism's sense-making activity.

Sense-making is the interactional and relational side of autonomy. An autonomous system produces and sustains its own identity in precarious conditions and thereby establishes a perspective from which interactions with the world acquire a normative status. Certain interactions facilitate autonomy and other interactions degrade it. In Merleau-Ponty's words: "each organism, in the presence of a given milieu, has its optimal conditions of activity and its proper manner of realizing equilibrium," and each organism "modifies its milieu according to the internal norms of its activity" (Merleau-Ponty 1963, pp. 148, 154). Sensemaking is behaviour or conduct in relation to environmental significance and valence, which the organism itself enacts or brings forth on the basis of its autonomy.

Whether we choose to call the sense-making of bacteria cognitive or proto-cognitive is not something we need to dispute here (see Thompson 2007, pp 158-162). The important point is that a living organism is a system capable of relating cognitively to the world (however we define cognition and wherever we place its biological emergence) because it is a sense-making system, and it is a sense-making system because it is an autonomous system.

Bacteria are the simplest kinds of living organisms and they exhibit both autopoiesis and sense-making. But their sense-making cannot be derived simply from their being autopoietic, for mere autopoiesis is not sufficient for sensemaking (Bitbol and Luisi 2005; Bourgine and Stewart 2004; Di Paolo 2005, this issue; Thompson 2007, pp. 122-127, 147-148). Rather, as Di Paolo (2005, this issue) has discussed, "adaptivity" needs to be added to autopoiesis in order to generate sense-making.

Mere autopoiesis - the operationally closed self-production of a chemically bounded network-provides only the all-or-nothing conservation of identity through material turnover and external perturbations to the system, but not the active regulation of interactions with the outside world. Sense-making is normative, but the only norm that autopoiesis can provide is the all-or-nothing norm of selfcontinuance, not the graded norms of vitality (health, sickness, stress, fatigue) implied by an organism's regulating its activity in ways that improve its conditions for autonomy (as when a bacterium swims up a sucrose gradient or swims away from a noxious substance). An adaptive autopoietic system, however, is one that can regulate its states with respect to its conditions of viability in its environment and thereby modify its milieu according to the internal norms of its activity (Di Paolo 2005). Autopoiesis and adaptivity are jointly sufficient for sensemaking, but mere autopoiesis is insufficient.

We can now say what sort of autonomy is required for sense-making and cognition. What is required is not autopoiesis but adaptive autonomy. In single-celled organisms such as bacteria, adaptive autonomy takes the form of adaptive autopoiesis. Multicellular animals with nervous systems embody more complex forms of adaptive sensorimotor autonomy. Thus it is adaptive autonomy that grounds the deep continuity of life and mind (Thompson 2007) and not autopoiesis as such.

\section{Neither Internalism nor Externalism}

The grounding of cognition in sense-making and sensemaking in adaptive autonomy do not imply either internalism or externalism about the processes of cognition. The internalist/externalist debate rests on assumptions that are foreign to the enactive approach.

The enactive approach is not internalist because it allows that the operationally closed networks that realize an autonomous sense-making system can extend beyond the brain, skull, or skin (see De Jaegher and Di Paolo 2007 for social cognition and Cosmelli and Thompson 2009 for the brain and consciousness). Yet one can deny internalism in this way without thereby embracing externalism (contrary to Hurley, in press). To see why we need to consider the assumptions built into the internalist/externalist debate.

Internalists claim that explanations of what constitutes cognitive processes need appeal only to internal factors (relative to some usually unexamined spatial boundary such as the skull). Externalists deny this claim. Yet externalists allow that what goes on entirely inside the head (e.g., some specific neural process) sometimes counts as a cognitive process; their strategy is to argue by counterexample that not every cognitive process can be explained by appealing exclusively to internal factors (see Hurley, in press). Furthermore, externalists often accept the assumption that what goes on entirely inside the head provides a paradigm of what is a cognitive process, such that if factors outside the head can be shown to have a comparable or equivalent status (e.g., by playing the same role in the production of behaviour), then those external factors count

\begin{tabular}{|l|ll|}
\hline Journal : Large 11245 & Dispatch : 24-11-2008 & Pages : 8 \\
Article No. : 9043 & $\square$ LE & $\square$ TYPESET \\
MS Code : TOPO02801-3 & $\square_{\text {CP }}$ & $\square$ \\
\hline
\end{tabular}


as part of the cognitive process. (This is the so-called parity principle introduced by Clark and Chalmers 1998). ${ }^{3}$

The enactive approach does not accept these assumptions. What goes on strictly inside the head never as such counts as a cognitive process. It counts only as a participant in a cognitive process that exists as a relation between the system and its environment. Cognition is not an event happening inside the system; it is the relational process of sense-making that takes place between the system and its environment. In Maturana and Varela's language (1980, 1987), cognition belongs to the 'relational domain' in which the system as a unity relates to the wider context of its milieu, not to the 'operational domain' of the system's internal states (e.g., its brain states). Of course, what goes on inside the system is crucial for enabling the system's cognitive or sense-making relation to its environment, but to call internal processes as such cognitive is to confuse levels of discourse or to make a category mistake (neurons do not think and feel; people and animals do).

There is a clear parallel here between the enactive approach and the phenomenological notion of intentionality (Varela et al. 1991, pp. 205-206; Thompson 2007, pp. 26-27). Intentionality is always a relation to that which transcends the present state of the system (where what transcends the system does not have to exist in the sense of being a real entity). In saying that the mind is intentional, phenomenologists imply that the mind is relational. 'Beingin-the-world' (Heidegger) and the 'lived body-environment' (Merleau-Ponty) are different ways of articulating this kind of relation. The spatial containment language of internal/external or inside/outside (which frames the internalist/externalist debate) is inappropriate and misleading for understanding the peculiar sort of relationality belonging to intentionality, the lived body, or being-in-theworld. As Heidegger says, a living being is 'in' its world in a completely different sense from that of water being in a glass (Heidegger 1995, pp. 165-166).

Di Paolo also makes exactly this point on behalf of the enactive approach in his contribution to this issue. His words bear repeating here:

Cognition is sense-making in interaction: the regulation of coupling with respect to norms established by the self-constituted identity that gives rise to such regulation in order to conserve itself. This identity may be that of the living organism, but also other identities based on other forms of organizationally closed networks of processes, such as sociolinguistic

\footnotetext{
${ }^{3}$ See Di Paolo, this issue, for an excellent critical discussion showing how the parity principle "relies both on simple prejudices about inner and outer as well as on intuitions about cognition" that "are inevitably tied to the boundaries between inner and outer that it wishes to undermine."
}

selves, organized bundles of habits, etc. Some of 306 these identities are already constituted by processes that extend beyond the skull. But in any case, cognition is always a process that occurs in a relational domain. Unlike many other processes (e.g. getting wet in the rain) its cognitive character is given normatively and asymmetrically by the self-constituted identity that seeks to preserve its mode of life in such engagements. As relational in this strict sense, cognition has no location. It simply makes no sense to point to chunks of matter and space and speak of containment within a cognitive system. Inspect a baby all you want and you'll never find out whether she's a twin.

\section{Cognition and Emotion}

Sense-making comprises emotion as much as cognition. The enactive approach does not view cognition and emotion as separate systems, but treats them as thoroughly integrated at biological, psychological, and phenomenological levels (Colombetti 2005, 2007, 2009; Colombetti and Thompson 2005, 2007; Thompson 2007). By contrast, the extended mind thesis and the debates it has engendered to-date have neglected emotion and treated cognition as if it were largely affectless problem solving or information processing (Adams and Aizawa 2008; Clark 2007).

Sense-making is viable conduct in relation to what has salience and value for the system. What has salience and value also has valence: it attracts or repels, elicits approach or avoidance. Such action tendencies in relation to value are the basis of emotion. Hence, as Walter Freeman argues, "emotion is essential to all intentional behaviours" (Freeman 2000).

To describe cognition as embodied action (Varela et al. 1991) implies that cognition comprises motivated action tendencies and thus is also essentially emotive. Motivated action, especially when it involves affect, is a mode of selfregulation. Cognition as embodied action is more a matter of adaptive self-regulation in precarious conditions than abstract problem solving. The point here is not to deny that we can and do engage in high-level problem solving. Rather, it is that this kind of narrow cognition presupposes the broader emotive cognition of sense-making.

Attention to the inseparability of emotion and cognition is an emerging trend in cognitive science. For example, Marc Lewis (2005) argues that appraisal and emotion processes are thoroughly interdependent at both psychological and neural levels (see also Colombetti and Thompson 2005). At the psychological level, one is not a mere means to the other (as in the idea that an appraisal is a means to the having of an emotion, and vice-versa); rather,

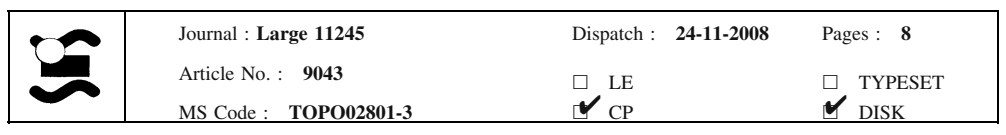


they form an integrated and self-organizing emotionappraisal state, an 'emotional interpretation.' At the neural level, brain systems traditionally seen as subserving separate functions of appraisal and emotion are inextricably interconnected. Hence 'appraisal' and 'emotion' cannot be mapped onto separate brain systems.

In a recent review, Pessoa (2008) provides extensive evidence from neuroscience that supports this view of the neural underpinnings of emotion and cognition. He presents three converging lines of evidence: (1) brain regions previously viewed as 'affective' are also involved in cognition; (2) brain regions previously viewed as 'cognitive' are also involved in emotion; and (3) the neural processes subserving emotion and cognition are integrated and thus non-modular. In Pessoa's view, "complex cognitive-emotional behaviours have their basis in dynamic coalitions of networks of brain areas, none of which should be conceptualized as specifically affective or cognitive" (Pessoa 2008, p. 148).

If affect and action tendencies are inseparable from cognition at neural, psychological, and phenomenological levels, then cognition cannot be either 'body neutral' or 'envatted,' in Shapiro's (2004) terms. 'Body neutrality' is the assumption that bodily features play no significant role in how or what an organism cognizes; 'envattment' is the assumption that there is a clearly defined interface between the body and the mind (Shapiro 2004, p. 169). Both of these assumptions clearly break down in the face of the integration of emotion and cognition (Colombetti 2007, 2009; Shapiro 2004, pp. 214-219).

Nevertheless, disagreement remains about the body's exact status in relation to cognition (Clark 2008). This issue brings us to our next contrast between the enactive approach and the extended mind thesis.

\section{The Body}

One way (though not the only one) to motivate the special importance the enactive approach gives to embodiment is to appeal to the dynamic interdependency between cognition and emotion (or more precisely between processes traditionally classified as 'cognitive' and ones classified as 'affective'). Complex cognitive-emotional behaviours'emotional interpretations' or 'appraisal-emotion amalgams' (Lewis 2005)-essentially involve organismic processes of self-regulation aimed at sustaining and enhancing adaptive autonomy in the face of perturbing environment events. As Damasio (1999) especially has emphasized, emotion is the way the brain and the rest of the body jointly sustain homeostasis throughout the organism's dealings with its environment.
Given that extended-mind theorists neglect emotion and view cognition as primarily high-level problem solving, it is not surprising that they also accord less importance to the biological details of embodiment than do other embodiedmind theorists (e.g., Shapiro 2004). Thus Andy Clark concludes that "the body, insofar as it is cognitively significant, turns out to be itself defined by a certain complex functional role," that of being "the locus of willed action, the point of sensorimotor confluence, the gateway to intelligent offloading [for problem-solving computations], and the stable (though not permanently fixed) platform whose features and relations can be relied upon in the computation of certain information-processing solutions" (Clark 2008, pp. 55-56). In keeping with functionalism generally, Clark advocates that we simply identify the body with this functional role (and with whatever can possibly realize this functional role). For the purposes of explaining cognition, the body is simply "whatever plays these roles in a unified information-processing economy" and it is "merely a contingent (and increasingly negotiable) fact about human embodiment" that the body is also a metabolic entity (ibid., p. 56).

This characterization of the body's functional role preserves the traditional functionalist conception of cognition as fundamentally distinct from emotion. Emotion nowhere figures in this account of the body and its cognitive capacities ("the body insofar as it is cognitively significant"). In this way, Clark's conception of cognition remains strongly allied with traditional (disembodied) cognitive science.

For this reason, we question Shapiro's use of the extended mind thesis to argue against the 'envattment' assumption that there is a clearly defined interface between the body and the mind (Shapiro 2004, p. 183). Shapiro's thought is that if the mind extends beyond the brain into the body and the environment, then the mind and the body "cannot be distinguished as separate components within a single system" and thus have no "clean interface" (p. 183).

What Shapiro overlooks, however, is that the extended mind thesis winds up treating cognition and emotion as if they were separate components that must interface because this thesis preserves the traditional functionalist conception of cognition.

As Shapiro discusses, the containment of the mind with respect to the body does not require spatial localization: "The mind could still count as envatted if the biological parts that realize it were spread across the body... If the parts that realize the mind all work toward the solution of similar problems, communicate with each other more than they do with other parts of the body, receive and send information from and to the body through clearly articulated channels, and so on, then the mind can be envatted

\begin{tabular}{|l|ll|}
\hline Journal : Large 11245 & Dispatch : 24-11-2008 & Pages : 8 \\
Article No. : 9043 & $\square$ LE & $\square$ TYPESET \\
MS Code : TOPO02801-3 & $\square_{\text {CP }}$ & $\square$ \\
\hline
\end{tabular}


despite not having a spatially localized realization" (Shapiro 2004, p. 214).

Clark's (2008) characterization of the functional role of the body treats cognition as functionally contained in precisely this way in relation to emotion. Cognition extends to include the sensorimotor body characterized in functional or computational terms, but is compartmentalized (envatted) in relation to the physiological body of emotion. Cognition and emotion remain cleanly separable.

We believe that the recent theories and findings from the psychology and neuroscience of emotion reviewed above count strongly against this envatted view of cognition. Instead, they support the enactive conception of cognition/ emotion as self-regulating and valenced sense-making (Thompson 2007, pp. 360-381; Varela and Depraz 2005).

Clark's assessment of the cognitive role of the body flows from the information-processing and functionalist models on which the extended mind thesis rests. As he writes, "The body is special. But we should understand its specialness through the familiar lens of our best information-processing models of mind and cognition" (2008, p. 58).

Here we come upon a fundamental difference between the enactive approach and the extended mind thesis. The enactive approach regards these information-processing models as limited. From the enactive perspective, their problem is fundamental: they do not explain autonomy and hence cannot explain cognition.

Information-processing models of the mind leave unexplained the autonomous organization proper to cognitive beings because they treat cognitive systems as heteronomous systems (Thompson 2007, pp. 43-60; Varela 1979; Varela et al 1991, pp. 139-140; see also Di Paolo and Iizuka 2008). These models characterize cognitive systems in terms of informational inputs and outputs instead of the operational closure of their constituent processes. As a result, they do not explain how certain processes actively generate and sustain an identity that also constitutes an intrinsically normative way of being in the world.

Cognition or sense-making is the intentional and normative engagement of the system with its environment. One of the basic propositions of the enactive approach is that being autonomous is a necessary condition for a system to embody original intentionality and normativity. Unless the processes that make up a system constitute that system as an adaptive self-sustaining unity, there is no perspective or reference point for sense-making and hence no cognizing agent. Without autonomy (operational closure) there is no original meaning; there is only the derivative meaning attributed to certain processes by an outside observer.

What relevance do these considerations have for the status of the body? Clark proposes that the body is "just one element in a kind of equal-partners dance between brain, body, and world, with the nature of the mind fixed by the overall balance achieved" (Clark 2008, pp. 56-57). For the enactive approach, the body (including the brain) leads in this dance because it is what realizes the autonomous organization necessary for individual agency and sensemaking. ${ }^{4}$

In making this statement, we do not assume that the brain is to be strictly identified with the central nervous system or that the body is to be demarcated by the skin. Both the nervous system and the body are compositionally plastic. They can alter their structure and dynamics by incorporating (taking into themselves) processes, tools, and resources that go beyond what the biological body can metabolically generate (e.g., artificial organs and neural and sensorimotor prostheses). We develop this point in the last section of our paper.

\section{Incorporation Versus Extension ${ }^{5}$}

The enactive approach allows that the living system considered metabolically can constitutively include resources and processes beyond its body. Di Paolo (this issue) gives a nice example. Certain insects can breathe underwater by trapping air bubbles with tiny hairs in their abdomen. The bubbles form a thin permanent layer of air (a plastron) around the body and act as a physical gill. As Di Paolo notes, "The mediation [of regulated environmental coupling] in cases like this is so intimately connected with vital functions that the living system itself might be called extended."

In these cases, the living system extends by dint of the body's capacity to incorporate environmental processes into the operationally closed network of processes that constitutes its autonomy. It is this incorporation (literally, a taking into the body) that extends the body and creates a new organ (the physical gill) for adaptive coupling with the environment. Incorporation is one way that the body can lead in the body-world dance.

Following De Preester (2008), we wish to distinguish between tools and aids that merely 'extend' the body and ones that the body 'incorporates' so that they become in effect prostheses. Resources that extend the body are familiar features of our environment-pens, scissors, cars, computers, and so forth. These entities are artifacts that we use and control in order to extend our abilities. Tools that

\footnotetext{
${ }^{4}$ Here we are speaking at the level of individual cognition/emotion. 4FL01 For social cognition and its dynamics, see De Jaegher and Di Paolo 4FL02 (2007).

4FL03

5 This section is greatly indebted to unpublished work by Helena De 5FL01 Preester. We thank her for making this work available to us. 5FL02
} 
the body incorporates also extend our abilities but they have a phenomenologically different status.

To explain the phenomenological status of incorporation we need to distinguish between two ways of experiencing the body - the body-as-object and the body-as-subject (Legrand 2006, 2007a, b). The body-as-object is the body perceived and recognized as mine (e.g., "These are my hands."). The body-as-subject is a structure of experience; it is that through which the world is experienced. As such, the body-as-subject is transparent: "The body is transparent in the sense that one looks through it to the world. At this level, pre-reflective bodily experience is precisely the experience of the world as given through the 'transparent body.' The latter is not perceived as an object but experienced specifically as a subject perceiving and acting, that is, in-the-world" (Legrand 2007b, p. 504).

We suggest that environmental resources that are incorporated gain this transparency. They are no longer experienced as objects; rather the world is experienced through them. The classic example is Merleau-Ponty's (1962) case of the blind man and his cane. Once skilled at using the cane, the blind man does not experience the cane as an object; instead, he experiences the world at the end of the cane. The cane has become transparent to him.

This sort of transparency also occurs for prosthetic limb wearers who report feeling things coming into contact with their limbs: "One of the major factors in my satisfaction with a new prosthesis is how little I feel it. That may sound strange, but to me, my prosthesis is an extension of my body. I can actually 'feel' some things that come into contact with it, without having to see them... It must 'feel' as close to not being there as possible' (Murray 2005, cited by De Preester 2008).

As De Preester (2008) discusses, recent evidence from neuroscience and psychology casts light on incorporation and phenomenal transparency. For example, a number of studies have shown that neural networks containing maps of peripersonal space can be significantly modified through tool use (Maravita and Iriki 2004; Maravita et al. 2003). The nonconscious body schema and the conscious awareness of the body can extend to include noncorporeal and inanimate objects (Berlucchi and Aglioti 1997). Studies of the so-called 'rubber hand illusion' also suggest that the feeling of body ownership can extend to prostheses (Tsakiris et al. 2006).

Based on these findings, we propose the following 'transparency constraint': For anything external to the body's boundary to count as a part of the cognitive system it must function transparently in the body's sense-making interactions with the environment. We also hypothesize that tools and aids that conform to transparency are incorporated into the neurophysiological body schema.
The transparency constraint is nontrivial. Sweeney Todd is an accomplished barber far exceeding his peers, but he may never experience the world through his scissors as Edward Scissorhands does. Although biological attachment is not a requirement for transparency, some kind of intimate coupling with the body's autonomous dynamics is necessary. Spelling out the forms this coupling can take is a difficult task, but from the enactive perspective the key constraint is that external resources be subject to active regulation by the body. Once again, the body has to be capable of leading the dance.

In conclusion, we propose that the transparency constraint can usefully inform research proceeding under the banner of the extended mind theory. It suggests a way to distinguish between environmental resources that the cognitive system simply uses instrumentally and resources that come to constitute the cognitive system over some stretch of time. It enables us to raise phenomenological questions that can in turn guide neuroscientific and psychological investigations. To what degree does Otto experience his notebook as an object and to what degree does the notebook function transparently as a way for him to experience himself in the world? To what degree has Otto's body schema incorporated his notebook? Has Otto's sense of body ownership extended to include the notebook?

These are the sorts of tractable questions that enactive and extended mind theorists should be trying to answer, not the questions posed in the dichotomous and inappropriate categories of inside versus outside.

\section{References}

Adams F, Aizawa K (2008) The bounds of cognition. Blackwell, Malden, MA

Berlucchi G, Aglioti S (1997) The body in the brain: neural bases of corporeal awareness. Trends Neurosci 20:560-564

Bitbol M, Luisi PL (2005) Autopoiesis with or without cognition: defining life at its edge. J R Soc Interface 1:99-107

Bourgine P, Stewart J (2004) Autopoiesis and cognition. Artif Life 20:327-345

Clark A (2007) Curing cognitive hiccups: a defense of the extended mind. J Philos 104:163-192

Clark A (2008) Pressing the flesh: a tension in the study of the embodied, embedded mind? Philos Phenomenol Res 76:37-59

Clark A, Chalmers D (1998) The extended mind. Analysis 58:7-19

Colombetti G (2005) Appraising valence. In: Colombetti G, Thompson E (eds) Emotion experience. Imprint Academic, Thorverton, UK, pp 103-126. Also published in Journal of Consciousness Studies 12:103-126

Colombetti G (2007) Enactive appraisal. Phenomenol Cogn Sci 6:527-546

Colombetti G (2009) Enaction, sense-making and emotion. In: Stewart J, Gapenne O, di Paolo E (eds) Enaction: towards a new paradigm for cognitive science. The MIT Press, Cambridge, MA

\begin{tabular}{|l|ll|}
\hline Journal : Large 11245 & Dispatch : 24-11-2008 & Pages : 8 \\
Article No. : 9043 & $\square$ LE & $\square$ TYPESET \\
MS Code : TOPO02801-3 & $\square_{\text {CP }}$ & $\square$ \\
\hline
\end{tabular}


661

662

663

664

665

666

667

668

669

670

671

672

673

674

675

676

677

678

679

680

681

682

683

684

685

686

687

688

689

690

691

692

693

694

695

696

697

698

699

700

701

702

703

704

705

706

707

708

709

710
Colombetti G, Thompson E (2005) Enacting emotional interpretations with feeling. Behav Brain Sci 28:200-201

Colombetti G, Thompson E (2007) The feeling body: toward an enactive approach to emotion. In: Overton W, Mueller U, Newman $\mathbf{J}$ (eds) Body in mind, mind in body: developmental perspectives on embodiment and consciousness. Lawrence Erlbaum, New Jersey

Cosmelli D, Thompson E (2009) Embodiment or envatment? Reflections on the bodily basis of consciousness. In: Stewart J, Gapenne O, di Paolo E (eds) Enaction: towards a new paradigm for cognitive science. The MIT Press, Cambridge, MA

Damasio AR (1999) The feeling of what happens: body and emotion in the making of consciousness. Harcourt Brace, New York

De Jaegher H, Di Paolo E (2007) Participatory sense-making: an enactive approach to social cognition. Phenomenol Cogn Sci 6:485-507

De Preester H (2008) On corporeal prostheses as an essential human characteristic. Presented at ESPRA 2: subjectivity and the body, 29 January-1 February 2008, Copenhagen. http://espra.risc.cnrs. fr/ESPRA2Home.htm

Di Paolo EA (2005) Autopoiesis, adaptivity, teleology, agency. Phenomenol Cogn Sci 4:429-452

Di Paolo EA (this issue) Extended life

Di Paolo EA, Iizuka H (2008) How (not) to model autonomous behaviour. Biosystems 91:409-423

Freeman WJ (2000) Emotion is essential to all intentional behaviors. In: Lewis MD, Granic I (eds) Emotion development, and selforganization. Dynamic systems approaches to emotional development. Cambridge University Press, Cambridge, pp 209-235

Heidegger M (1995) The fundamental concepts of metaphysics: world, finitude, solitude (trans: McNeill W, Walker N). Indiana University Press, Bloomington

Hurley SL (in press) Varieties of externalism. In: Menary R (ed) The extended mind. Ashgate, Aldershot

Legrand D (2006) The bodily self: the sensori-motor roots of prereflexive self-consciousness. Phenomenol Cogn Sci 5:89-118

Legrand D (2007a) Pre-reflective self-as-subject from experiential and empirical perspectives. Conscious Cogn 16:583-589

Legrand D (2007b) Pre-reflective self-consciousness: on being bodily in the world. Janus Head 9:493-519

Lewis MD (2005) Bridging emotion theory and neurobiology through dynamic systems modeling. Behav Brain Sci 28:169-194

Maravita A, Iriki A (2004) Tools for the body (schema). Trends Cogn Sci 8:79-86

Maravita A, Spence C, Driver J (2003) Multisensory integration and the body schema: close to hand and within reach. Curr Biol 13(13):531-539

Maturana HR, Varela FJ (1980) Autopoiesis and cognition: the realization of the living. Boston Studies in the Philosophy of Science, vol 42. D. Reidel, Dordrecht
Maturana HR, Varela FJ (1987) The tree of knowledge. The biological roots of human understanding. Shambala Press/New Science Library, Boston

Merleau-Ponty M (1962) Phenomenology of perception (trans: Smith C). Routledge Press, London

Merleau-Ponty M (1963) The structure of behavior (trans: Fisher A). Dusquene University Press, Pittsburgh, PA

Murray CD (2005) The social meaning of prosthesis use. J Health Psychol 10:425-441

Pessoa L (2008) On the relationship between emotion and cognition. Nat Rev Neurosci 9:148-158

Ruiz-Mirazo K, Moreno A (2004) Basic autonomy as a fundamental step in the synthesis of life. Artif Life 10:235-259

Shapiro LA (2004) The mind incarnate. The MIT Press, Cambridge, MA

Thompson E (2004) Life and mind: from autopoiesis to neurophenomenology. A tribute to Francisco Varela. Phenomenol Cogn Sci 3:381-398

Thompson E (2007) Mind in life: biology, phenomenology, and the sciences of mind. Harvard University Press, Cambridge, MA

Tsakiris M, Prabhu G, Haggard P (2006) Having a body versus moving your body: how agency structures body-ownership. Conscious Cogn 15:423-432

Varela FJ (1979) Principles of biological autonomy. Elsevier North Holland, New York

Varela FJ (1991) Organism: a meshwork of selfless selves. In: Tauber A (ed) Organism, the origin of self. Kluwer, Dordrecht, pp 79-107

Varela FJ (1997) Patterns of life: intertwining identity and cognition. Brain Cogn 34:72-87

Varela FJ, Bourgine P (eds) (1991) Toward a practice of autonomous systems. In: Proceedings of the first European conference on artificial life, the MIT Press, Cambridge, MA

Varela FJ, Depraz N (2005) At the source of time: valence and the constitutional dynamics of affect. In: Colombetti G, Thompson E (eds) Emotion experience. Imprint Academic, Thorverton, UK, pp 64-81. Also published as a special issue of Journal of Consciousness Studies 12:64-81

Varela FJ, Maturana HR, Uribe R (1974) Autopoiesis: the organization of living systems, its characterization and a model. Biosystems 5:187-196

Varela FJ, Thompson E, Rosch E (1991) The embodied mind: cognitive science and human experience. The MIT Press, Cambridge, MA

Wheeler M (in press) Minds, things, and materiality. In: Renfrew C, Malafouris L (eds) The cognitive life of things: recasting the boundaries of the mind. McDonald Institute for Archaeological Research, Cambridge

\begin{tabular}{|l|lll|}
\hline Journal : Large 11245 & Dispatch : 24-11-2008 & Pages : 8 \\
Article No. : 9043 & $\square$ LE & $\square$ TYPESET \\
MS Code : TOPO02801-3 & $\square_{\text {CP }}$ & $\checkmark$ DISK \\
\hline
\end{tabular}

